\title{
From academic discovery to industrial applications: Innovation and success in materials science and engineering
}

\section{Philip Ball}

\begin{abstract}
Turning good ideas and discoveries in the laboratory into commercial and industrial products that succeed in the marketplace is a fraught affair. Most apparently promising leads never get that far, being derailed by lack of funding, unexpected technical hitches, excessive cost, consumer indifference, and other hurdles. This difficult transition without doubt weeds out some ideas that simply don't have what it takes, but some casualties might have become success stories if the developmental process had been better handled. So what can you do to give your exciting discovery the best possible chance of being the start of something big? And how can universities, companies, and institutions prevent useful innovation from falling by the wayside?
\end{abstract}

\section{Introduction}

You've done the benchtop work, you've optimized the parameters, and your prototype system - a new solar cell, a ceramic coating, a component for biomedical prostheses-works perfectly. It's all set to commercialize. What now?

As anyone who has been in this position knows, you're on the brink of the most perilous part of the journey. Sure, making the prototype was a hard slog, but you knew where you were going and what challenges you'd face. You're an academic (let's say), so this is your job-this is what you wrote that grant proposal for; this is what was needed to get that paper published. But if you're going to see that product used by manufacturers and companies worldwide, you now need really serious money. You have to scale up production of the thing cobbled together in the lab so that it becomes a commercially viable proposition.

It's a big risk, because, until the device or material gets out into the marketplace, no one knows if anyone will buy it. Who is going to take that kind of risk? Where does the money for scaling up come from, and how can you achieve scale-up for a fraction of the cost of making the prototype? Arguably most important of all, how do you find your market and attract customers? And will the market pay the price you need?

Facing these questions, innovations developed in academic labs typically confront a "valley of death": a barren wasteland where R\&D funding has stopped before a potential product has been commercialized and can provide revenue (see Figure 1). This is where a great many promising materials systems come to grief. How can the valley be crossed?

\section{Starting a spin-off: Luck versus planning}

Although universities are now almost universally eager to see researchers create start-up companies to commercialize their innovations - not least because this brings in both money and kudos-it's easy to get it wrong (see the sidebar on Market failures). Ceramic scientist Jon Binner of the University of Birmingham in England, past president of the UK Institute of Materials, Minerals and Mining, has had some successes with spin-offs and commercial applications, such as ceramic foams for bone grafts and ultratough nanostructured zirconia. ${ }^{1}$ But he admits that the harvest seems meager in comparison to the time and money invested in his basic research. In retrospect, he says, the lessons seem obvious "and really shouldn't have needed learning"- but the problems never seemed so clear at the time. For example, you need to have a dedicated team, not just a doctoral student or two working on the project, and this team needs to include the individual who did the original research. You need to know your market and get your timing right. You also need luck-lots of luck.

Binner said that it's vital to involve industrial partners as early as possible. Otherwise, you risk spending lots of time and effort on some aspect of the problem that industrialists 


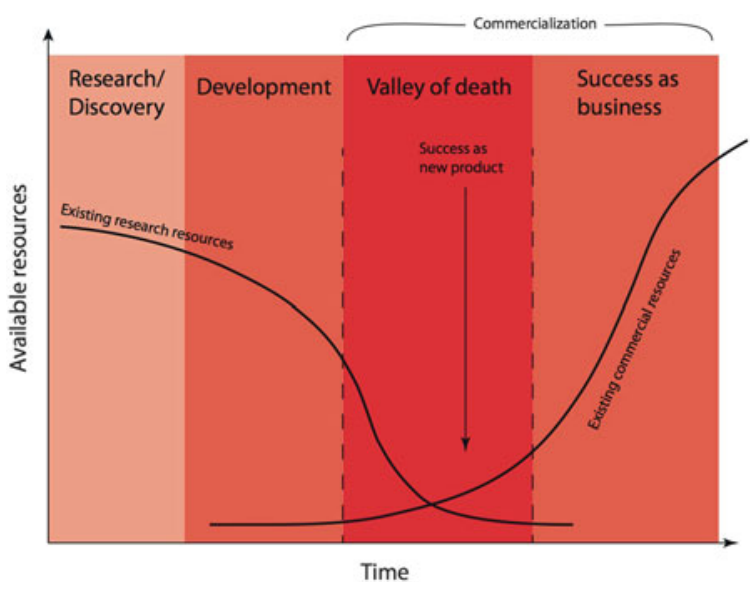

Figure 1. Illustration of the "valley of death" showing where $R \& D$ funding has stopped before a potential product has been commercialized and can provide revenue.

simply won't care about. The same advice goes for the industrialists: Get in there quickly, because "academics are notorious for feeling that they know what is best" and are all too apt to develop a scientifically sweet answer to a technical or production challenge that is industrially hopeless. The simpler the technology, the better, because every new level of complexity increases the costs. It is a particularly bad idea to try to introduce both a new product and a new method for processing it at the same time.

Given the contingencies that start-ups face, Silicon Valley entrepreneur Steve Blank, who has launched two semiconductor electronics companies and consulted for clients from Pixar to military-intelligence suppliers, is an advocate of the so-called "lean model," in which detailed and rigid business plans are ditched in favor of a fleet-footed and adaptive approach. ${ }^{2}$ Instead of a plan, he advises, make a sketch. Then go out and test it on potential partners and customers. Listen to what they say, and adjust your approach accordingly - in short, stay agile. You're not "like a big company only smaller," Blank tells would-be start-ups, so don't act like one. Indeed, even big companies have sometimes adopted the lean model. GE took this customer-led route in preference to conventional marketing for rolling out its (now-defunct) molten-salt Durathon battery technology, a high-energy-density cell that uses a molten salt as the electrolyte, in 2011-2012.

Materials-based innovations are not exactly magnets for venture capital. "As a venture-capital investor, I could pour [US] \$100 million into a materials company over 10 years before I learned whether they can achieve product-market fit," said Bryce Meredig of Citrine Informatics in Redwood City, Calif., a company established to help researchers circumnavigate some of the challenges and hurdles in the conventional pipeline of materials development. "The same validation at a software start-up might only require [US] \$1 million and a year or two." Citrine aims to use materials databases to accelerate breakthrough discoveries and their commercialization in areas ranging from batteries and photovoltaics to aerospace superalloys and screen coatings for personal electronics.

Setting up a spin-off business is not a hobby - it sucks up a lot of time, even for the academic scientist who opts to act merely as a consultant and lets professional experts take care of the business side. That, said physicist Brian Tanner, Dean for University Enterprise at Durham University in England, isn't always understood. Many people say that they're in it for the long haul, he said, until they realize what that means. For an innovation in materials science to reach the market takes "a long, long time" warned Erich Ruetsche, who manages intellectual property (IP) at IBM's research laboratory in Zurich, Switzerland. Time scales of a decade are typical, he said.

It's tempting, too, to imagine that the key challenges are mainly technical. Tanner said that the really hard part is getting funds not for a proof of concept but for the next stage of setting up a commercial team: "getting the idea into a business proposition that is investable." This is where costs rise sharply, partly because it generally means employing people from outside. Consequently, it's where the risks are highest.

The way the process works in China today is similar. Hui-Ming Cheng, a specialist in carbon nanostructures at the Chinese Academy of Sciences' National Laboratory for Materials Science in Shenyang, has been involved in several transfers of technology from his institute to industries. This might involve sharing profits, said Cheng, or a straight sale to a company. In some cases, a company pays in advance for the development of a particular technology, subject to an agreement on ownership of the results. "Quite a few Chinese companies, big and small, national and private, as well as private investors, are willing to invest in new materials and technologies," said Cheng. Indeed, he is more upbeat about the prospects of investment in China than many researchers seem to be in other countries. "We are working with at least four companies on R\&D of carbon nanotubes, graphene, energy storage, thermal management, and so on. I'd say that a good technology with a bright market has no worries at all about money nowadays."

Yet, the gap in knowledge and understanding between researchers and industrialists is one he encounters too. "Investors and companies quite often ask us to help them or to develop the technology into products," said Cheng. "But we are researchers, and it's difficult for us to do processing, optimization, market investigation, and mass production."

Can the difficult journey across the valley of death be made less risky and haphazard? Meredig thinks so. "At Citrine, we're interested in approaching the fundamental limit, whatever it might be, of how quickly materials can be propelled from early-stage laboratory R\&D to scale-up and commercialization," he said. He admits, though, that "there exists no repeatable process for anticipating and solving these challenges."

Finding an industrial partner, or venture capital for a start-up, to carry an academic innovation through the valley of death is not the only way that materials discoveries reach the market. Rather, the idea that industry takes the basic innovations and 


\section{Market failures}

"My memory is of spending more time chasing the next bit of funding than I spent working on the technical issues," said Jon Binner, looking back ruefully at Ceratronics, the spin-off that he set up in 1992 to commercialize a ceramic device for measuring moisture availability in soils. With hindsight, he said, he got the timing wrong. "While we had the basic ideas worked out, we were far short of having an even remotely working prototype." Things always take longer than you think, he said, and it's essential to have a reasonably secure source of funding from the outset.

But perhaps the biggest mistake was a failure to identify the right market. In the UK, water was not expensive enough to make it worth the development costs of a device that could help plants use it more effectively, rather than just irrigating more extensively. There was potentially more demand in South Africa, but the South African currency, the rand, was too weak at that time to make development viable. They should have explored possibilities in richer but water-poor countries such as Israel and Australia, Binner said, or recognized that the one market where a device like this really would pay off was in greenhouse-based horticulture.

The importance of getting the product and customer set right is crucial, Paul Drzaic of Apple Inc. agreed. "From personal experience, the technology can be great, but if the application is chosen improperly or the timing is wrong, then a great technology can fail to achieve market success, even with plenty of funding and external interest." The figures are stark: According to Shikhar Ghosh of the Entrepreneurial Management Unit of Harvard Business School, 75\% of all start-up companies fail.

There are many lessons to learn from what goes wrong. For example, make your dealings with industrial clients as transparent as possible, Binner advised. When his ceramic-foam start-up, Dytech, was asked to provide a sample of alumina foam to a large aerospace company for a confidential application, at short notice and with no questions asked, they discovered many years later that, without knowing the specific materials requirements, they had chosen the worst possible sample to offer. No wonder it failed the evaluation miserably. What they needed was a nondisclosure agreement that could have allowed for more open negotiations. Industries can worry without good cause that academics can't keep things confidential, said Binner. If a project, or information about it, really is confidential, he said, then "it should not be happening in a university environment" in the first place. Such relationships depend on developing and maintaining trust, and this applies both ways. If there's a nagging problem with a process or product, don't try to sweep it under the rug. "Trust takes so long to build up but is such an easy thing to lose."

A common pitfall for materials applications is the failure to acknowledge the resistance in industry to changes in manufacturing and processing routes-sometimes with good reason. There are bleak prospects for even a potentially innovative and superior method of making a material or component if it requires a complete reorientation of many years of established industrial practice. In one case, Binner and his co-workers devised a solution-based method of coagulating ceramic powder suspensions for forming components with complex shapes, using organic additives inspired by the way chocolate is made from cocoa particles. It looked wonderful on paper: The conditions were close to ambient, the tools were inexpensive, and the components could be sintered to high densities and strengths. But no company was interested, because the ceramics industry is focused on dry rather than wet processing, partly because of the long drying times and the associated high energy needs. Sadly, wet forming seems to be of interest mostly to academics. "There are many wet-forming routes developed in laboratories around the world that have met similar fates," said Binner, "with little or no commercialization even after a decade or more of a working system being developed."

If the drivers of change are sufficiently strong, then profound changes can occur. For example, the need for a new dielectric material for microchip manufacture (hafnia rather than silica) necessitated a profound change in the way chips were produced layer by layer, but there seemed to be no alternative, but industry must face such a compelling, even desperate, necessity before it will take on board the investments that such change requires.

Even with the best-laid plans, success or failure often depends on luck: on factors beyond anyone's ability to control or predict. Binner was involved in research on the use of nanostructured zinc oxide in electronic components such as varistors that seemed to tick all the right boxes as a commercial product. But just as the manufacturing process was entering the scale-up stage, the Irish company due to start production was bought up, production was moved to China, and the whole idea was dropped by the new owners. "More often than not, something goes wrong," Binner admits. 
discoveries provided by academia and turns them into commercial products presents only part of the picture. Ever since the emergence of the modern chemical industry in the mid-19th century, companies have recognized the value of having in-house scientists who conduct basic research. Plenty of advances in materials science and engineering unfold entirely within the industrial sector. Indeed, according to Paul Drzaic, senior manager of emerging display technologies at Apple and Chair of the MRS Bulletin Editorial Board, large companies more commonly develop new technologies internally rather than simply commercializing those invented in university labs. Here, the pressures and constraints, and therefore the solutions, can be rather different (see the sidebar on Innovation in-house).

\section{The right place at the right time}

Materials scientist John Rogers of the University of Illinois at Urbana-Champaign has more experience than many at turning innovation into potential applications. His work on soft and flexible electronic circuits, made from polymers using simple printing technologies, has possible uses ranging from biomedicine to wearable clothing to lighting (see Figure 2). Rogers considers himself fortunate to have done his early training in the 1990s in "one of the few places then embracing entrepreneurial activity," Massachusetts Institute of Technology (MIT), which, said Rogers, "really did involve combined excellence in science and engineering." "I lucked out," he admits. MIT ran a competition for young researchers for the best business plan based on their work, and this enabled Rogers to start a spin-off company based on a new laser technique for studying thin-film microelectronics, which was eventually acquired by Philips Analytical (now PANalytical). "That was the sort of thing I wanted to be able to do in the future," he said.

Yet it turned out that the most useful application of the technique (high-resolution measurement of the thickness of metal films) was completely different from what Rogers and his colleagues envisioned (mechanical characterization of polymer films) - an example of how successful spin-off companies often don't actually make their big money on the product or idea they started with. As Steve Blank said, "Business plans rarely survive first contact with customers."

\section{Innovation in-house}

Gorilla Glass, developed by Corning Inc. for scratchproof touchscreen displays in smartphones and tablet computers, is a material devised and developed almost solely within industry. It is an aluminosilicate alkali glass in which ion exchange of sodium for potassium adds stresses to the amorphous material that produce greater hardness without sacrificing toughness. The next-generation Gorilla Glass 4 promises to withstand being dropped onto a hard surface, ending the days of gazing at a crack-laced screen. ${ }^{4}$

Few products better illustrate how demand, not curiosity, often drives innovation. The story of Steve Jobs badgering Corning to come up with a product that would meet his vision for the iPhone is well-known. His request motivated Corning scientists to look again at the ultratough glass called Chemcor that the company had tried to market in the 1960 s to a world that, at that point, had no need for it. The iconic Gorilla Glass emerged in 2007 from a close collaboration between Corning scientists and Apple, and it is hard to imagine such rapid progression from idea to product ever taking place through the channels of academic research.

Conventional wisdom has it that the golden years of basic research within industry have passed. And there is no question that the capacity for it at industrial labs such as Bell Labs and IBM Research has dwindled in the past two decades. But there are positive stories too, Gorilla Glass among them. General Motors has displayed a steadfast commitment to research on thermoelectric materials, for example, and IBM researchers have conducted fundamental studies in lithium-air battery technology. A 2014 survey conducted by the European Union reported that European companies were expected to increase R\&D investment by an average of $4.2 \%$ up to 2016 despite the ongoing economic recession. ${ }^{5}$

In theory, basic research within a big company doesn't have to cross a valley of death before becoming a commercial product. But there are still plenty of in-house hurdles to jump. "Most big companies operate using some sort of stage-gate process," explained Paul Drzaic of Apple Inc. "New developments are tested with incrementally more challenging goals and larger expenditures, with the option to kill a project or pass [it] to the next stage."

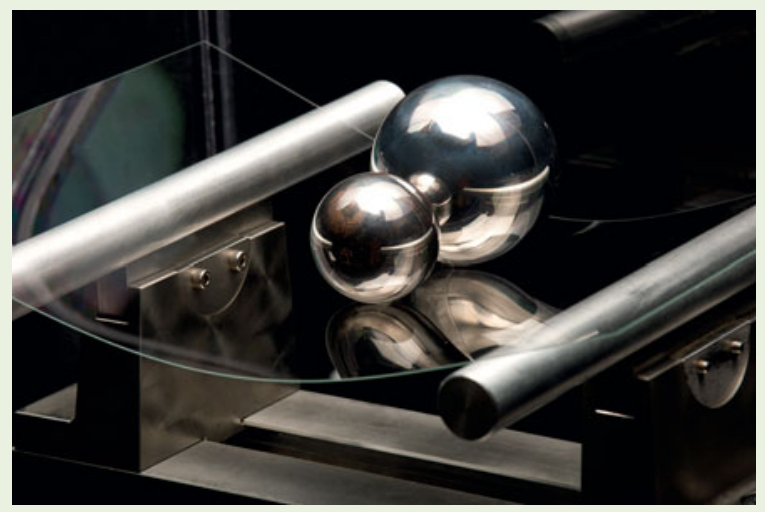

A piece of Corning's Gorilla Glass undergoing a flexibility test in the laboratory. Image courtesy of Corning Incorporated. 


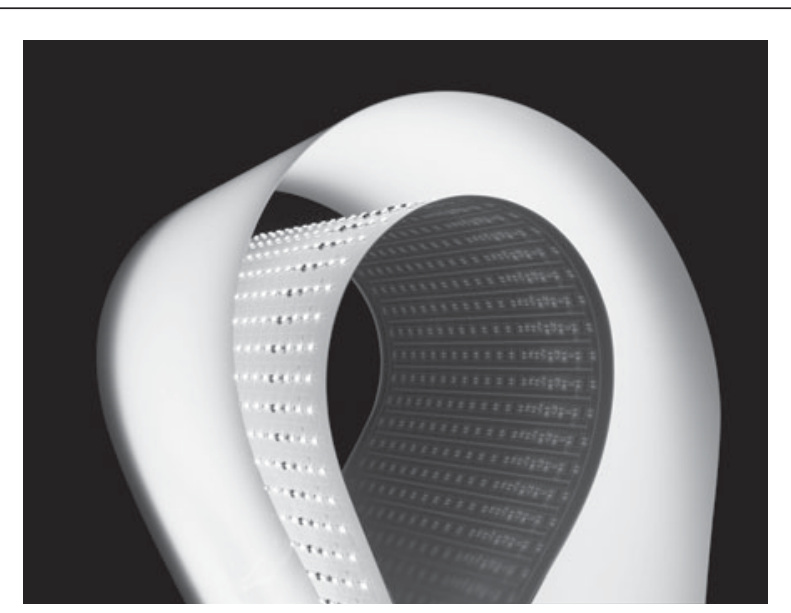

Figure 2. Flexible light-emitting diode light sheet (12-mm pitch, 8.5-in. width) from Cooledge Lighting.

"If I had my way, every scientist who wants to work with industry would [take] an Economics 101 course," said Binner. Academics typically just don't understand economic issues such as working within profit margins, he said. But although it's definitely a good thing for students to be offered courses in entrepreneurship, said Rogers, there are limits to what can be achieved that way. "As a graduate student, you're pretty loaded down with other stuff already," he admits. And there is no substitute for actual experience. "It might be aspirational to think you can teach this stuff at university-you've got to get out and do it."

Steven Moss, an engineer at the Aerospace Corporation in El Segundo, Calif., which provides information on space engineering to military, civil, and commercial customers, and a member of the MRS Bulletin Editorial Board, is even more skeptical. "From my perspective, academics mostly do not understand the particulars of product development, including the valley of death," he said. "Any number of universities have developed organizations designed to encourage entrepreneurship and development of small companies, but these are mostly job shops for former students that may take a discovery up to the valley of death before selling the discovery to another commercial firm. It is rare that one of those firms takes an idea from discovery to application."

Moss feels that academics tend to be enamored of the fundamental physics, chemistry, and materials science of discoveries and can become advocates for technologies without a solid understanding of what it takes in terms of cost, yield, reliability, and so forth for a product to be manufacturable. "Academics can drift easily into irrelevant exotica," Rogers agreed. Meredig pointed out that many research groups are still studying lead-based thermoelectric materials, for example, even though environmental regulations in Europe make such materials commercial nonstarters.

Although industry isn't going to get ideas from academia in a market-ready form, the research required to get them there - optimization of parameters, streamlining of processing, identification of cheaper raw materials, say - doesn't generally hold much appeal or glory for academics. 'It's not clear that you can do good work on a well-known problem within academia," said Rogers. University departments are good at finding new concepts, without necessarily knowing how they might be used. But academic research often doesn't relate to what industry needs. It might present the performance of the best samples rather than typical ones, for example, and the kinds of questions that confer status and lead to invited talks and tenure are not necessarily the ones that matter for applications. "Citrine would be tremendously interested in a study in which a research group synthesized 500 unrelated crystalline compounds and systematically measured their bulk moduli," said Meredig, "but such mundane parametric work is not interesting or novel from an academic perspective."

Schemes that expose young researchers to the demands of business can never be the whole solution, as no individual will ever know all that is required to bring an idea to fruition. It is also about creating the right kind of environment. Solid-state physicist Bertram Batlogg of the Swiss Federal Institute of Technology (ETH) in Zurich said that during the many years he spent working at Bell Laboratories in Murray Hill, N.J., he hoped at lunchtime to sit down with colleagues who worked at all stages of product development: people who were familiar with the engineering challenges of making microprocessors, as well as people who worked on electronic band-structure calculations. That, Batlogg said, is never something that would have occurred by collecting the 30 brightest researchers in academic departments. After completing postdoctoral work at Harvard, Rogers joined Bell Labs too and agreed that it truly offered an opportunity to encounter "science plus engineering, all under one roof." Not only did Bell Labs already understand the market needs, he said, but its various parent companies over the years, starting with AT\&T, had their own manufacturing capability. It has always been "in the best tradition of condensed-matter physics to be mindful of applications," said Batlogg. But the advantage at Bell Labs was in having both expertise and mechanisms to realize them easily at hand.

Sadly, the situation at Bell Labs and many other technology companies has changed significantly since the late 1990s, when they began to take a more short-term approach to product development that left less room for exploratory fundamental work. "Bell Labs shrank to something unrecognizable," said Rogers. Compared to the era of the big research laboratories from the 1960 s to the 1990 s, there has been "an enormous dwindling of the capacity to do fundamental research within industry," said polymer scientist Tom McLeish of Durham University. Much of that basic research now needs to come from universities. "Industry is increasingly outsourcing fundamental materials R\&D to academia," agreed Meredig.

Moss feels that this trend has caused deep problems. "One of the main economic issues affecting all of science is the divestment of research labs by many companies," he said. 
"The overall effects of downsizing, new emphasis on near-term results, and changes in research directions at various commercial labs have had a severe negative impact on the availability of high-quality industrial research positions in the US." He feels that many entrepreneurs now have a very short-term view and are unduly attracted to trendy hot topics. "Government funding officers are not immune to this trend," Moss added.

In Japan, polymer scientist Takuzo Aida at The University of Tokyo worries that industry has become extremely conservative and risk-averse. There have long been concerns that Japan's conformist and hidebound corporate culture has been inimical to entrepreneurship — it can appear selfish in a culture that frowns on egotism — but Aida thinks the climate has been particularly inclement in recent years. "Japan is now one of the most conservative countries on the Earth for converting innovative materials discovered in academia into successful commercial products," he said. Top technology companies are full of "nonchallenging and highly conservative employees who are content simply to repeat existing ideas with small modifications." Once this happens, he says, it's very difficult for a big company to recover. As a result, Aida said, "Japan is a very difficult country for venture business to grow."

Takao Someya, an electrical engineer in Tokyo who works on organic electronics, agreed that "compared to the US and Europe, Japanese start-up companies were behind up until now," but he thinks that there are now some promising start-ups emerging from academia. He is also rather optimistic about materials innovation in industry, citing, for example, advances in nanocarbon structural materials (now used in aerospace engineering) at Toray Industries, optical filters developed by Fujifilm for liquid-crystal displays, Mitsubishi's work on organic photovoltaic cells, and organic light-emitting diode (LED) materials being produced by Idemitsu Kosan and Sumitomo Chemical Company. Perhaps in this case, Japan's economic stagnation has helped to make entrepreneurship seem more attractive: Whereas, previously, top graduates could be sure of a good job in a major corporation (and would come under strong parental pressure to take it), big companies can no longer offer the opportunities or security that they once did. All the same, Japan has a long way to go. Some observers say that it has the least accepting attitude toward start-ups and entrepreneurs in all of Asia, and those that exist struggle to establish themselves globally: There's no domestic model for young Japanese innovators to look to.

\section{Who owns the knowledge?}

Some valuable research conducted within industry never sees the light of day because of an almost paranoid concern for secrecy about the knowledge gained. "Some organizations are so critically concerned with IP that they will not allow any staff member to present work at an MRS meeting," said Moss. Others might permit that much, but not publication even in a conference proceeding, let alone a peer-reviewed journal. Sometimes, this obsession with secrecy risks defeating the object of actually selling the product, said Moss. "If you are attempting to determine if a product meets reliability standards, you must understand how the product is constructed. But the restrictions sometimes placed upon buyers of products would make it almost impossible to perform assessments of reliability."

Universities can take very different approaches to the IP rights in start-ups that spring from academic research, sometimes to their detriment. Some encourage academics to set up companies at the drop of a hat and tend to believe that ownership of the IP is vital. "Companies set up in this environment can sometimes be ill-conceived and poorly managed," warned a 2012 statement prepared by the UK's Royal Academy of Engineering (RAE) ${ }^{3}$ in response to a report on support of innovation by the British government. "Universities with more experience may come to recognize that ownership of IP is not as important as value gained through exploitation."

In any case, there's little to be gained by holding on too tightly to a good idea. "A stranglehold on control of either the IP or the company can dissuade the investment or commitment of the other people necessary to make the company successful," said Drzaic. Binner advises being realistic: Even if you're lucky enough for your innovation to make it to market, licensing royalties are unlikely to be larger than $\sim 2-3 \%$. When a university researcher spins off his or her own company, there's the issue of how the institution and the individuals share the revenue. This can become fractious unless the ground rules are very clear at the outset. For example, Durham University takes the view that "knowhow is also IP," explained Tanner. Any knowledge gained as a result of an individual's employment is deemed to be, in some sense, the property of the university - whereas, say, a molecular biologist who sets up a company to make better lawnmowers has a right to consider the knowhow all her own.

IBM's Zurich research laboratory, where important applied discoveries from high-temperature superconductivity to scanning probe microscopy were made, has fostered close ties with a number of academic institutions, including nearby ETH. It practices a very open approach of joint IP ownership, said Ruetsche, which allows either partner to develop applications without the need for consultation. Any successful product demands collaboration with others to build a complex, viable ecosystem, he said; that was how IBM's personal computers became possible, in partnership with two small companies - a software firm called Microsoft and a chip manufacturer called Intel. If IP is too strongly protected, Ruetsche said, no one will pick it up and use it.

\section{Infrastructure and institutions}

Whether a new technology is viable depends on the existing infrastructure in the market it enters: whether, for example, the necessary materials can be easily accessed through local supply networks. Fuel-cell and battery development in the UK, for instance, have been hindered by the lack of companies able to scale-up production of the right materials, whereas no such problem exists for the long-established British automotive industry. 
The local skills base is also crucial. Plastic Logic, the company formed to commercialize pioneering work at the University of Cambridge on polymer electronics (see Figure 3), decided to manufacture its products outside the UK and chose to do so in Dresden, Germany, partly because of the availability of skilled workers and of the support that could be offered from the German network of Fraunhofer Institutes and the German government. In the UK, the planning and construction time scales for manufacturing facilities were deemed too long. Likewise, when the materials discovery company Ilika, developed at the University of Southampton (UK), wanted to manufacture hydrogen-storage materials, it was forced to do so in the United States because of the lack of local resources needed for scale-up.

Another big challenge is to ensure that, as McLeish put it, industry and academia are "impedance-matched," so what comes out of one will flow smoothly into the other. At the moment, there are often big gaps in levels of knowledge and traditions of practice: a gulf in approach and knowhow between fundamental research and the daily realities of manufacturing (see the sidebar on Reaching the SMEs). The experience at Durham University shows that universities and industries can find ways to collaborate effectively: The university currently has a close and productive relationship with Procter \& Gamble. The challenge is that the needs of industry are often highly interdisciplinary, which might not marry well with the compartmentalization of knowledge in academia. Procter \& Gamble apparently came to Durham University in the United Kingdom because, there, the company did not face the prospect found in the United States of having to build a team from scratch: There was already plenty of interaction between the right departments. The message for universities is clear: if they want to work well with industry, they need to break down disciplinary barriers within their own walls.

What's more, collaborations like this are likely to be more secure and successful if they have many strands to them. The old-style interactions between academia and industry tended to be more individual-based, said Tanner, which meant that they were fragile: If a company representative moved on, the link was broken. "Deep relationships" are needed, he said. He estimated that, at present, there are about 90 separate collaborations between Durham University and Procter \& Gamble.
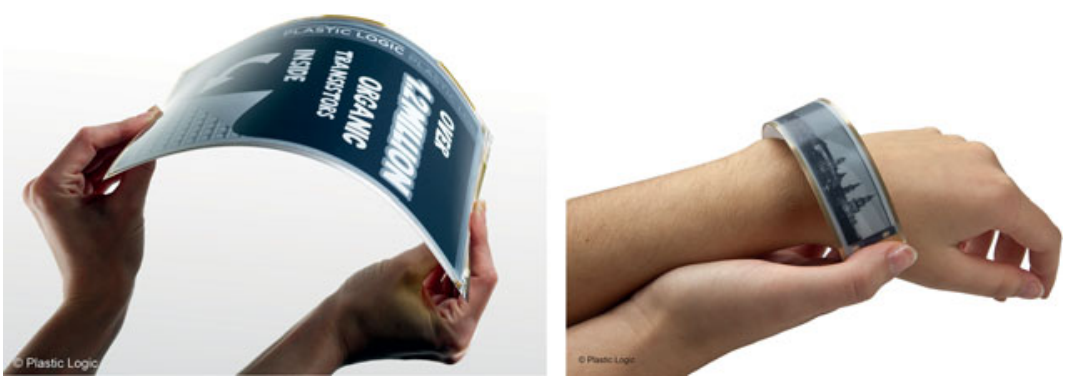

Figure 3. Flexible plastic electrophoretic displays. Images courtesy of Plastic Logic.
This also makes the interaction more robust to shifts in company policy, for example, when it becomes necessary to tighten belts in economically hard times.

Whereas institutions might enjoy the status and potential revenue from a successful spin-off (although neither might turn out to be as substantial as they might hope), why should an academic bother with what might seem a distraction from career-advancing opportunities of publishing striking fundamental research? McLeish said that industrial collaboration is actually good for that research: The idea that knowledge flows one way from basic science to applications, although it underlies a great deal of policy about knowledge transfer, is a "fairy tale." "It's symbiotic," he said. "Far more intellectual ideas come back the other way," from applications to fundamentals. He attests that his own research in polymer science has been enriched by information coming from industry - as, for example, when questions concerned with industrial processing and rheology of low-density polyethylene enabled him to develop a better understanding of the topological aspects of polymer entanglement. "There are great benefits to industrial collaboration, because interesting phenomena pop up in industrial research that open up fantastic scientific questions," McLeish said. Rogers believes, moreover, that research done with applications in mind is simply better, more complete research. "Science is best done with an eye toward technological impact," he said. You might not get rich this way, but your research will get richer.

\section{The role of government}

Because the risky step from prototype to commercial product is often taken by start-ups and small and medium-sized enterprises (SMEs), governments have a role to play in fostering a climate where such companies can survive among big competitors. SMEs, said McLeish, typically exist in a "hand-tomouth" situation and can easily go under. Their plight has been particularly difficult during the global economic crisis, and, still today, such enterprises are finding it hard to secure loans and support from banks. In the UK, the government has introduced the Enterprise Investment Scheme to offer tax incentives for investors in SMEs. According to the RAE's 2012 statement, however, some investors are too short-termistthey "start looking for the exit route from a spin-off company at the time of creation and do not think about growing it into a large organization." This, said the report, has dissuaded investors from supporting innovative research, which often takes much longer to turn a profit.

"Properly designed government funding schemes can be of tremendous assistance in the process of crossing the valley of death," said Binner. But by the same token, bad government interventions can be fatal. In the UK, he said, there has been constant change in the funding and investment environment within which scientific innovation tries to take off. 


\section{Reaching the SMEs}

Although academics sometimes have a woeful grasp of what a manufacturer can realistically work with, the shortcomings can work the other way around too. Industry, especially small- and medium-sized enterprises (SMEs), can get locked into conventional methods and ideas that do not necessarily keep pace with changing scientific understanding. Tom McLeish at Durham University calls this a problem of impedance matching, by analogy with electrical circuits.

In his area of polymer science, big companies such as Dow and Mitsubishi have been able to move away from empirical searches for new materials to a more rational approach based on computer modeling - there is now "a suite of software that allows for materials design in silico," McLeish said. Although this is all well and good, many actual polymer products - plastic bottles for example - are made not by the giants such as Dow but by polymer-processing SMEs. And "they don't move on in terms of understanding materials," said McLeish. "They are buying materials on the selection criteria of two generations ago." This, he says, is rather like deciding to buy a computer based on the criterion that it must be blue. A blue computer would meet that specification even if it had no memory.

For polymers, the equivalent of choosing by color is selecting according to the melt-flow index, the ease with which a molten thermoplastic flows. "It's completely useless," said McLeish. There are actually many other figures of merit that affect processing, but "we haven't found a way of pipelining all this great polymer science that would save money and energy and make better products." SMEs need figures of merit, he recognizes, but it is hard to change the culture so that they use the best ones. He plans to collaborate with some people from the polymer processing industry to work on making a device that can test polymers "for the processing aspects that matter" and come up with new figures of merit that are not too far removed from the one that processing firms already know. It shouldn't be very expensive to do-but there's no denying that this type of practical research is not seen as very glamorous compared with the glory of finding some clever new material, so such work, though important, gets overlooked.
"Every minister wants to leave their fingerprints on it," he said. "In just over a decade, we've been through three different systems." But whereas any system can be adapted to the good if it is simply left alone, "constant change means you're always on the learning curve and not reaching the stage of getting something useful out of it."

He cites the German system of the Fraunhofer Institutes as a good example of how to enable innovation to become application (see the sidebar on The German model). The Fraunhofer-Gesellschaft (Fraunhofer Society) exists explicitly "to transform scientific findings into useful innovations," and its 66 institutes cover topics from biomedical engineering to machine tools to wind energy. Research at the Freiburg Institute for Solar Energy Systems, for example, has been instrumental in pushing up the efficiency of photovoltaic cells based on III-V semiconductors and making Germany the European leader in commercial solar power.

The Fraunhofer Institutes occupy precisely that difficult territory between universities and industry - where, in many countries, innovative ideas face the valley of death. But although the German approach is widely regarded with admiration bordering on envy, it is more or less unique in the world and can't easily be exported, according to Michael Stelter, deputy director of the Fraunhofer Institute for Ceramic Technologies and Systems in Dresden. Even though there are a few Fraunhofer Institutes in the United States affiliated with American universities, Stelter thinks that trying to transfer the same approach wholesale to the US “probably won't work, at least without reshaping the whole innovation system." The German Fraunhofer Institutes take up the niche that US universities aim to fill with spin-off companies, which are now expected to provide the institutions with much of their revenue. Meanwhile, the Fraunhofer Institutes gear their strategy to the SMEs that make up the majority of German industry, not the giants like General Motors or Samsung that dominate in the United States and South Korea and which rely on their own R\&D. Because of such differences, when the R\&D organization Battelle tried to replicate the German system in the US in the 1980s and 1990s, it simply didn't work — no one could work out what such institutes would be for, said Stelter.

Besides, said IBM's Ruetsche, the German model of compartmentalizing responsibilities in the innovation pipeline doesn't work for everything. Sometimes, problems in fundamental science come to light at a later stage — not everything can be resolved on the drawing board. So there needs to be a feedback loop between the basic research and product development - it's not a linear process.

"The government role in enabling technologies to cross the valley of death is crucial," said Moss. It's not enough to assume that market forces will take care of this. "There are many projects with social value for which the market is too small to ensure that they will mature." Flat-screen televisions and cell phones will do fine in the marketplace, but other technologies without a mass market will struggle. For example, said Moss, in the aerospace industry, the total market for some 


\section{The German model}

The German system of technological innovation is systematic - and mostly highly effective for that reason. Basic research is the responsibility of the universities and the state-funded Max Planck Institutes, the latter receiving almost all of their approximately $€ 2$ billion funding from federal sources. From these institutions, said Michael Stelter of the Fraunhofer Institute for Ceramic Technologies and Systems in Dresden, "we expect basic research and Nobel prizes." No one, meanwhile, expects Nobels from the Fraunhofer Institutes: They are there to bridge the gap between basic science and commercial products. Arising from a collaboration of postwar institutes in Munich 65 years ago, the Fraunhofer Institutes have a function found almost nowhere else in the world.

They receive just a quarter of their budget from the German government - the rest has to be acquired in commissions from commercial customers. The institutes are highly decentralized: Each operates essentially like a private company, albeit not for profit. They set their own objectives and market approach and buy their own tools and resources. "There's a lot of freedom," said Stelter. This makes them extremely agile and adaptive to customers' needs. Their eye is on the medium term: on ideas that can expect to find commercial applications in three to five years.
"We know what companies are thinking and what their needs are," said Stelter. Companies are deterred from using new materials and processes by knowing nothing about how to test or simulate them. Academic labs, meanwhile, lack the resources to make prototypes and launch the kinds of pilot projects that industries want to see before they will take the risk of a new technology. Whereas, in other countries, this scale-up demands high-risk venture capital, Fraunhofer Institutes can provide it at a much lower risk. Even if a particular idea fails to bear fruit, the investment is not wasted: The resources, like the hot isostatic press used at the Dresden facility, remain in place for another project.



Fraunhofer Institute for Production Technology located in Aachen, Germany. microelectronic or optoelectronic devices can be numbered in the dozens. Moreover, he said, the market is not good at anticipating disruptive technologies.

Yet the valley of death isn't necessarily a bad thing in itself. It "acts as a filter, taking out poorly conceived propositions," the RAE statement explained, so "any change in policy to support the commercialization of products, services, and processes must be wary of artificially prolonging the lifetime of those weaker ideas."

Some researchers argue, however, that the rhetoric of a valley of death is itself outmoded and unhelpful. It conjures up the idea that one needs to be an intrepid explorer venturing into the unknown, facing despair and risking calamity. But as Australian civil servant Paul Harris, previously deputy director of the H.C. Coombs Policy Forum at The Australian National University, pointed out, the valley is not empty. "People and institutions exist that are already working to broker and translate knowledge in ways that are useful to society," he said, citing the Australian government's Cooperative Research Centres program as an example. "Government has a very important role in creating and funding the right kind of institutions that can do the connecting to most effectively achieve desired societal outcomes," said Harris. "This boundary work is a profession in its own right, with distinct processes and culture and ways of measuring performance." You need not cross the valley alone.

At the core of many of these issues is the question of what is the most appropriate and supportive setting for innovations to become applications. Some say that this isn't, and shouldn't be, what universities are about - that all their technology-transfer offices and IP lawyers are mistaking the role of higher education and academic research, which is to feed the pool of innovation and to train up the talent that industry needs, rather than to try to be commercial agents in their own right. Others would argue that the old picture of academia as a fertile but unworldly resource for a monolithic industry of big companies is obsolete and that the economy benefits from more intimate collaborations that blur the boundaries between pure and applied research. In the end, there is probably no one-size-fits-all solution. But for researchers, the strongest message seems to be that there can be tremendous intellectual satisfaction and benefits to getting involved in taking your smart ideas to the market-but you need to be realistic about the prospects, and recognize that you can't do it all yourself. You'll need to get real about getting real. 


\section{References}

1. J. Binner, in Advanced Processing and Manufacturing Technologies for Structural and Multifunctional Materials VII, T. Ohji, M. Singh, Eds. (Wiley, New York, 2013), pp. 161-176.

2. S. Blank, "Why the Lean Start-Up Changes Everything," Harvard Business Review (May 2013), https://hbr.org/2013/05/why-the-lean-start-up-changeseverything/ar/1 (accessed September 2015)

3. Bridging the "Valley of Death": Improving the Commercialisation of Research (Royal Academy of Engineering, London, February 2012), http://www.
engineeringthefuture.co.uk/government/pdf/ETF_Response_BridgingTheValley OfDeathInquiry_Feb2012.pdf (accessed September 2015).

4. "Corning to Highlight Advanced Glass Innovations for Consumer Electronics at CES 2015," http://www.corninggorillaglass.com/en/news/news-releases/324 (accessed September 2015).

5. "The 2014 Survey on R\&D Investment Business Trends" (Rep. EUR 26909 EN, Institute for Prospective Technological Studies, European Commission, Seville, Spain, 2014), http://iri.jrc.ec.europa.eu/survey14.html (accessed September 2015).



Vacul chan

Build-to-Print or 3D Model

Aluminum or Stainless Steel

One-Off or Production Quantities

High or Ultra-High Vacuum

Single Wall or Water-Cooled

CMM and RGA Inspection

ISO 9001-2008 Certified

ASME U Stamp Certified

Over 6000 standard products

to complete your system

Nor-Cal Products

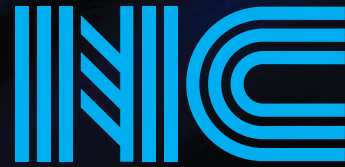

$800-824-4166$

530-842-4457

WWW.n-G.eOm

Where technology takes shape 


\section{$\mathrm{M}|\mathrm{R}| \mathrm{S}$}

\section{Advances}
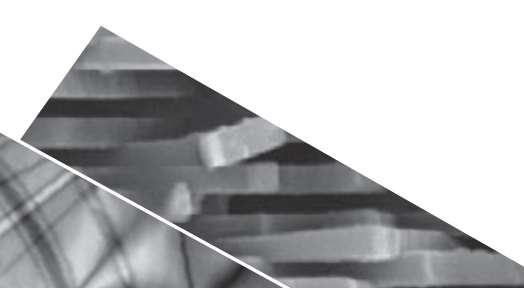

12

0

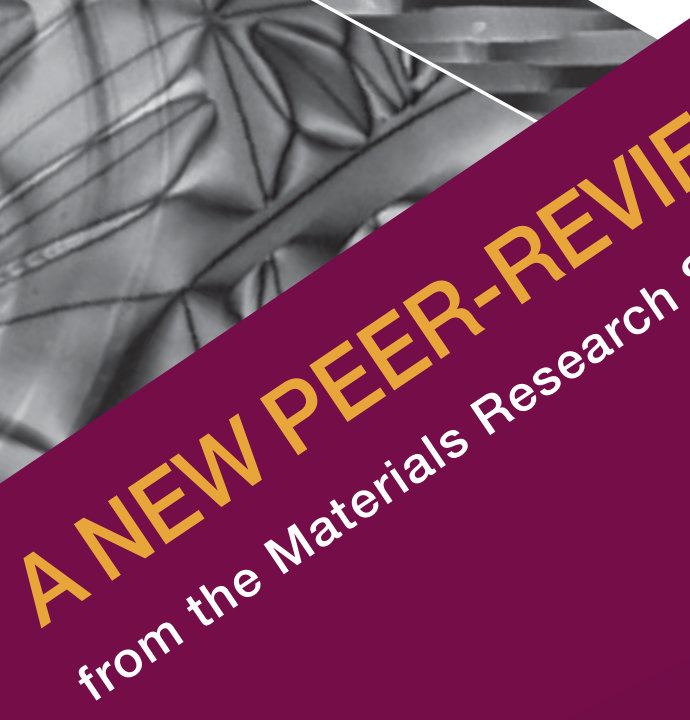

- devoted to publishing new and emerging materials science

- designed to reflect the way materials researchers work, write, publish and share their results

- editorial leadership ensures rapid peer review and speed of publication

- immediate global distribution alongside the MRS portfolio of world-class, peer-reviewed publications

- FREE to all MRS members

\section{Inaugural Content}

Available December 2015



